\title{
Effect of hydrogenation on deformation behaviour of ferritic-pearlitic steel studied by digital image correlation method
}

\author{
M. Stamborská*, J. Lapin, O. Bajana \\ Institute of Materials \& Machine Mechanics, Slovak Academy of Sciences, \\ Dúbravská cesta 9, 84513 Bratislava, Slovak Republic
}

Received 1 March 2016, received in revised form 15 July 2016, accepted 18 July 2016

\begin{abstract}
The effect of hydrogenation on room temperature tensile deformation behaviour of ferritic-pearlitic steel was studied. The process of hydrogenation was realised by annealing in flowing hydrogen followed by a fast cooling to room temperature. The room temperature tensile deformation behaviour of hydrogenated and annealed specimens was studied by the digital image correlation (DIC) method. Tensile elongation and reduction of the area were measured on the surface of cylindrical specimens coated with random speckle patterns using stereo CCD camera system. DIC elongation data were related to the data measured by an extensometer touching the specimen gauge section. The data from the DIC method were used for calculations of true stress-true strain tensile curves. Numerical simulations of strain fields within the gauge region of the specimens using finite element method were validated by the experimental data from the DIC method.
\end{abstract}

K e y words: mechanical properties, hydrogenation, microstructure, digital image correlation, finite element analysis

\section{Introduction}

Low carbon structural steels are widely applied in many engineering applications due to their low cost, good plasticity, viscosity, and sufficiently high level of mechanical properties. It has been found in a majority of control-rolled steel plates, bars or pipes that the microstructure is composed of alternating layers of banded ferrite and pearlite structure $[1,2]$. Ferrite-pearlite microstructures are also found in the intermediary state of the hot-rolled strips required for the production of the newest high-strength steels such as dual phase (DP) and transformation induced plasticity (TRIP) steels $[3,4]$. It has also been found that at room temperature the main diffusive path for hydrogen in a ferrite-pearlite structure is along the ferrite grain boundaries or interfaces between ferrite and pearlite. The pearlite colonies act as effective barriers to hydrogen diffusivity $[2,5]$.

Strain and displacement of structural materials are critical parameters for engineering and construction projects. However, measuring these parameters sometimes requires a difficult choice between conventional techniques, like accuracy, simplicity and cost must all be balanced. Digital Imaging Correlation (DIC) is a technique which may prove to be ideally suited for the study of crack propagation and material deformation in real-world applications, as it has the potential to become a cheap, simple and accurate solution. Classical tensile tests can provide only limited information about deformation behaviour of materials. Tensile specimens of metallic materials experience elastic deformation, plastic yielding, necking instability, and neck growth eventually leading to fracture due to a decrease in the load bearing capability. In order to understand tensile deformation behaviour related to intrinsic and extrinsic properties of materials, not only experiments using precise machines and sensors but also the deep interpretation of the deformation curves, specimen geometries, and specific testing con-

*Corresponding author: tel.: +421 23240 1058; e-mail address: stamborska.michaela@gmail.com 
ditions are important. Contactless sensing digital image correlation (DIC) optical method for tracking and image registration technique allows accurate $2 \mathrm{D}$ and $3 \mathrm{D}$ measurements of a gauge section of specimens during tensile testing and can provide new information about tensile deformation behaviour of materials [610]. The additional data obtained during testing can be used to understand more deeply whole tensile deformation process including calculations of local elongation, local contraction and redistribution of strain fields on the surface of the specimen. Hence, application of the DIC method for tensile testing of classical ferritic-pearlitic steels is of great interest to extend the existing knowledge about the deformation behaviour of this widely used group of materials.

The aim of this article is to study the effect of hydrogenation on the tensile deformation behaviour of low-carbon ferrite-pearlite steel. DIC method is applied for tracking, image registration and 3D measurements of changes in gauge section of specimens during tensile testing at room temperature. The achieved experimental results are supported by numerical calculations of the strain fields on the surface of tensile specimens using experimental data from DIC measurements as well as redistribution of strains within the gauge section using finite element analysis (FEA).

\section{Experimental procedure}

The studied ferritic-pearlitic steel was received in the form of cylindrical bars with a diameter of $10 \mathrm{~mm}$. The chemical composition of these bars was determined by glow discharge surface analyser LECO GDS $750 \mathrm{~A}$.

Tensile specimens with threaded heads, gauge diameter of $5 \mathrm{~mm}$ and a gauge length of $30 \mathrm{~mm}$ were prepared by lathe machining. The gauge section of the specimens was polished to a roughness better than $0.3 \mu \mathrm{m}$. The annealing of the specimens was carried out at a temperature of $550^{\circ} \mathrm{C}$ for $8 \mathrm{~h}$ in flowing argon or hydrogen. After annealing the specimens were rapidly cooled to $400^{\circ} \mathrm{C}$ in argon and then cooled into water. Hydrogen content was measured by LECO ONH836 analyser using small samples with a weight of $1 \mathrm{~g}$, which were cut from cylindrical samples with a diameter of $5 \mathrm{~mm}$ and length of $30 \mathrm{~mm}$ annealed with the tensile specimens in argon or hydrogen.

Microstructure examination of the tensile specimens before testing was performed by scanning electron microscopy (SEM) with JEOL JSM-6610 microscope. Samples for SEM were prepared by conventional metallography methods.

Quantitative metallography for the hydrogenated and annealed specimens was performed on digital optical micrographs using computerised image analyser and software SigmaScanPro.

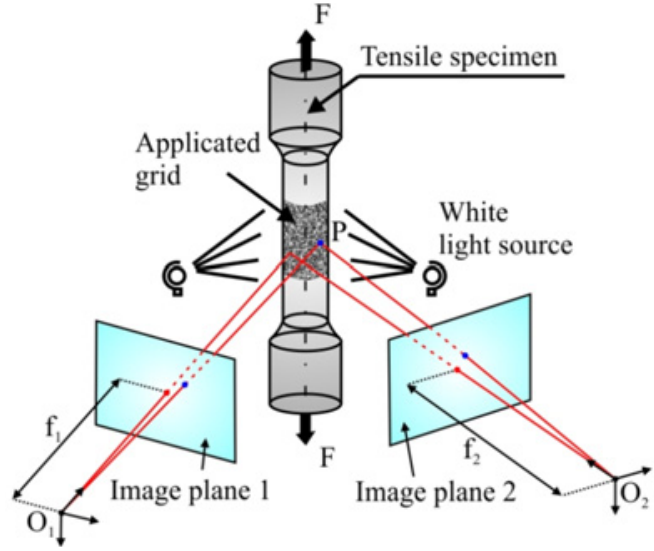

Fig. 1. Schema of 3D digital image correlation method for the cylindrical tensile specimen.

Room temperature tensile tests were carried out on threaded-head cylindrical specimens with a gauge diameter of $5 \mathrm{~mm}$ and gauge length of $30 \mathrm{~mm}$ at an initial strain rate of $1 \times 10^{-3} \mathrm{~s}^{-1}$ using Zwick/Roell Z100 tensile machine. The tensile tests were run until specimen fracture. Elongation of the specimens was measured by extensometer MAYTEC touching the surface of a gauge section of the specimen. The deformation was also measured by $3 \mathrm{D}$ digital image correlation (DIC) method using two high-speed CCD cameras MCR-2048-53 2/3", as seen in Fig. 1.

DIC is an optical method which measures deformation on an object's surface (Fig. 1). The method tracks the changes in grey value pattern in small neighbourhoods called subsets during deformation [9-12]. The surface pattern on tensile specimens was created by spraying a white based colour on the gauge section and spattering random black colour speckles on this basic layer. The applied DIC software divides the observed surface area into smaller areas called facets. The speckles copy deformations of the surface, and they move together with the surface during tensile deformation. Displacement of the speckles and corresponding strains were calculated through correlation of corresponding facets on the digital frame at the position before and after the deformation [12-16]. System realises calculations with the assistance of correlation algorithm based on the pseudo-affine coordinate transformation of object points from one picture to the second one. If displacement vectors of all points and reference outline are known, then it is possible to calculate the strain fields. The strain fields can be determined directly by the derivative of displacement of adjoining points or by analysis of local facets bending [10].

The strain fields were also determined by finite element analysis (FEA) [17-19]. The input data required for the elastic-plastic model in FEA such as the Young's modulus, Poisson's ratio, true stress, true 
Table 1. Chemical composition of the studied steel (wt.\%)

\begin{tabular}{cccccccccccc}
\hline $\mathrm{C}$ & $\mathrm{Mn}$ & $\mathrm{Si}$ & $\mathrm{P}$ & $\mathrm{S}$ & $\mathrm{Cr}$ & $\mathrm{Ni}$ & $\mathrm{Cu}$ & $\mathrm{Co}$ & $\mathrm{Zr}$ & $\mathrm{Al}$ \\
\hline 0.33 & 0.85 & 0.26 & 0.021 & 0.016 & 0.089 & 0.039 & 0.053 & 0.018 & 0.024 & 0.013 \\
\hline
\end{tabular}

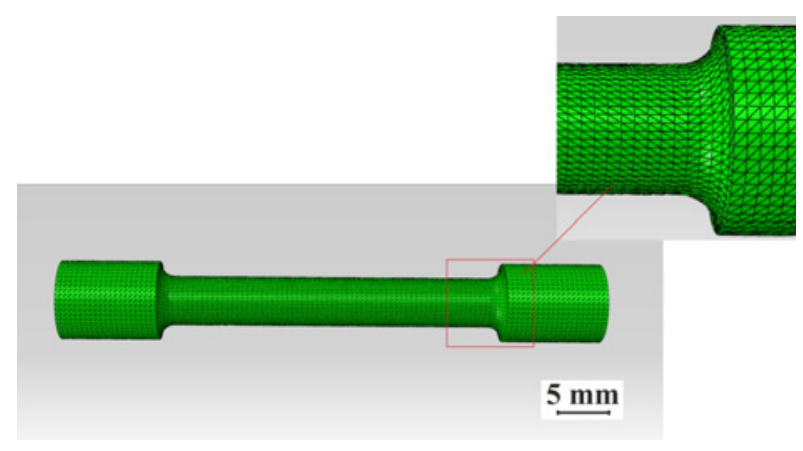

Fig. 2. Finite element mesh applied for the cylindrical tensile specimens with a detail of a mesh.

plastic strain, and strain hardening curve of the studied steel were determined experimentally by the tensile tests. Figure 2 shows the finite element mesh generated on the tensile specimens. For 3D analysis, the second-order tetrahedral elements with a size of $0.5 \mathrm{~mm}$ were used for the selected geometry of tensile specimens.

\section{Results and discussion}

\subsection{Microstructure before tensile testing}

Table 1 summarises the results of GDS measurements of the chemical composition of the as-received bars. The studied original state of material fulfils the requirements for the medium carbon steel according to the Slovak Technical Standards STN 411550 (DIN 17100 St 55) and is frequently used for the production of seamless tubes.

Figures 3a,b show the typical grain microstructure on longitudinal sections of the tensile specimens annealed in hydrogen and argon before deformation, respectively. Similar grain morphology was also observed on transversal sections of the tensile specimens indicating negligible anisotropy of the bars before tensile testing. The microstructure of the both types of tensile specimens consists of slightly elongated ferritic grains and pearlitic colonies before tensile testing (Fig. 3).

The average content of hydrogen in the specimens hydrogenated and annealed in argon is measured to be $(1.45 \pm 0.25)$ wt.ppm and $(0.32 \pm 0.12)$ wt.ppm, respectively. These values indicate that the studied steel is not prone to an intensive hydrogenation at the studied annealing temperature. As shown by Chan and
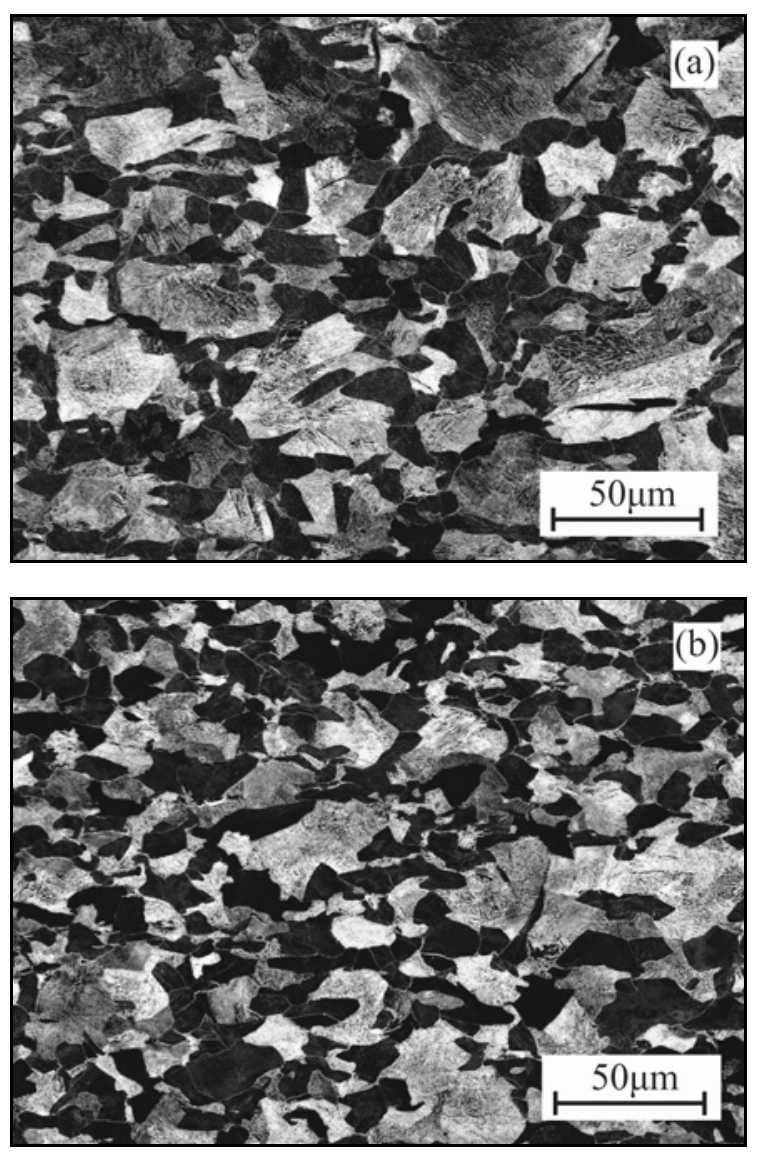

Fig. 3. SEM microstructure of the tensile specimens (a) hydrogenated and (b) annealed before testing.

Charles [5], the ferrite/pearlite and pearlite/pearlite interfaces represent effective hydrogen trapping sites in ferritic-pearlitic steels. On the other hand, the pearlite colonies act as effective barriers to hydrogen diffusivity $[2,5]$.

The microstructure of the tensile specimens is characterised by a shape factor, size and volume fraction of coexisting ferritic grains $(F)$ and pearlitic colonies $(P)$. The shape factor $F$ indicating the circularity of the grains on $2 \mathrm{D}$ projection is defined in the form

$$
F=\frac{4 \pi A}{P^{2}}
$$

where $A$ and $P$ is the area and perimeter of the ferritic grain or pearlitic colony, respectively. The statistical analysis of experimental data leads to a shape factor of $(0.52 \pm 0.01)$ and $(0.54 \pm 0.01)$ for the ferritic 

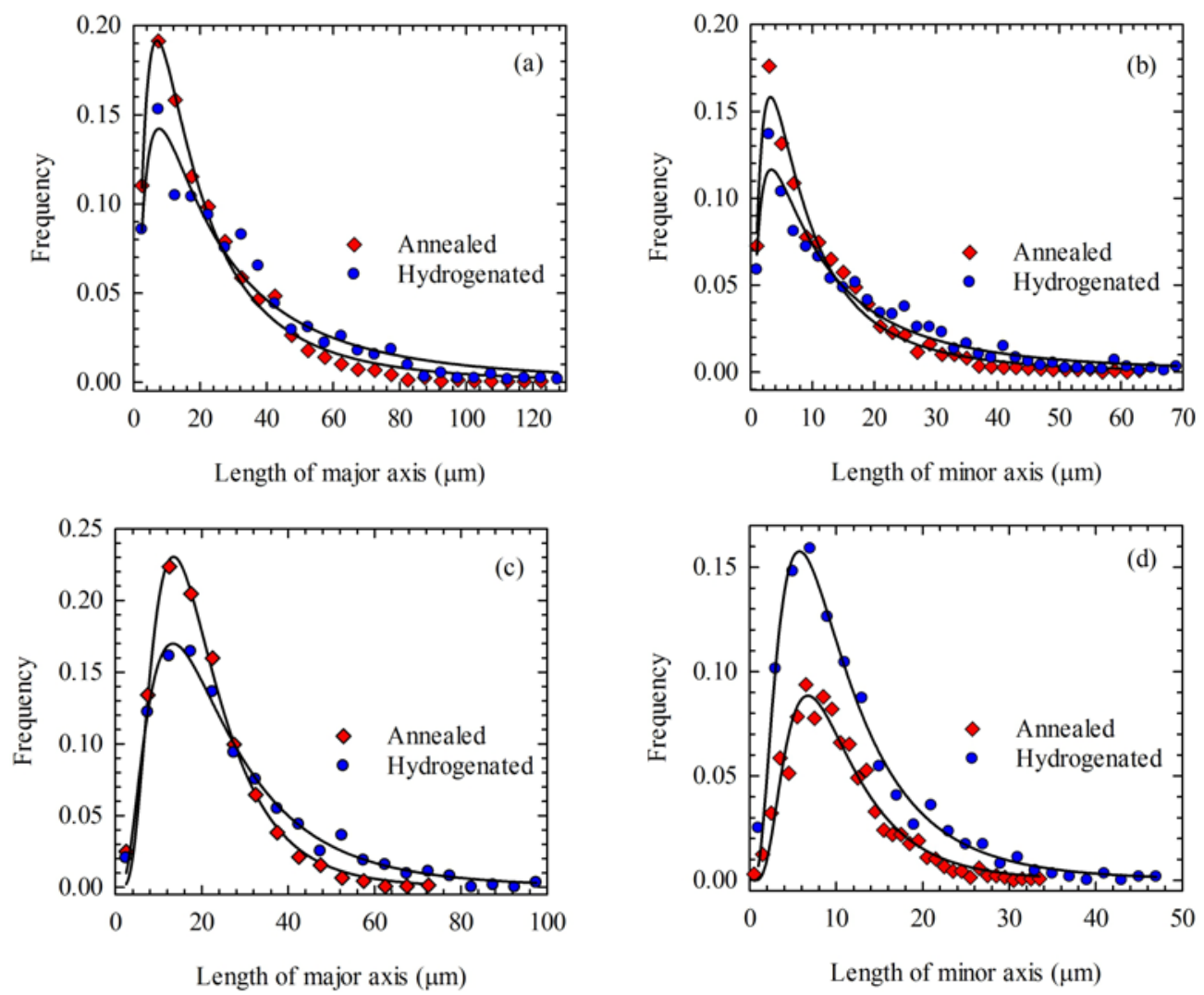

Fig. 4. Log-normal distribution curves of measured size of ferritic grains and pearlitic colonies: (a) major axis of pearlitic colonies, (b) minor axis of pearlitic colonies, (c) major axis of ferritic grains and (d) minor axis of ferritic grains.

grains and pearlitic colonies, respectively. The shape factor of about 0.5 indicates slightly elongated grains and colonies, which can be characterised by their major and minor axis. The measured length of the major and minor axis of the ferritic grains and pearlitic colonies (minimum 800 measurements for each type) can be well fitted by a log-normal distribution function, as seen in Fig. 4. The correlation coefficients of these fits are better that $r^{2}=0.97$. The mean values of length of the major and minor axis are indicated in Figs. 4a-d. It is clear that the applied annealing in hydrogen or argon has no significant effect on the mean size of ferritic grains and pearlitic colonies of the tensile specimens before testing. The volume fraction of the ferritic grains and pearlitic colonies is determined to be $(51.1 \pm 0.8)$ vol. $\%$ and $(48.9 \pm 0.9)$ vol. $\%$, respectively, which corresponds very well to the volume fraction of coexisting phases according to the $\mathrm{Fe}-\mathrm{Fe}_{3} \mathrm{C}$ phase diagram [20].

\subsection{Tensile deformation behaviour}

Figure 5 shows the typical tensile engineering stress-strain curves of the specimens annealed in hydrogen and argon tested to fracture. The stress-strain curves of the specimens annealed in hydrogen do not exhibit clear yielding point. The offset yield strength is

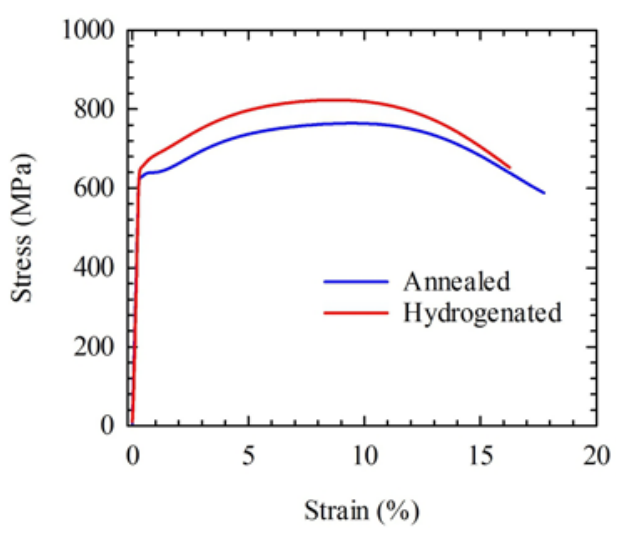

Fig. 5. Room temperature tensile stress-strain curves.

determined as the stress corresponding to $0.2 \%$ plastic deformation. Table 2 summarises average values of offset $0.2 \%$ yield strength (YS), ultimate tensile strength (UTS), elongation $(A)$, reduction of area $(Z)$ and the maximum value of local strain $\left(\varepsilon_{\max }\right)$ calculated from five tensile specimens tested for each type of annealing. As seen in Table 2, the yield strength and ultimate tensile strength for the hydrogenated specimens are higher by about $6 \%$ than those of the specimens annealed in argon. The average values of plastic 
Table 2. Room-temperature tensile properties

\begin{tabular}{|c|c|c|c|c|c|c|c|c|}
\hline \multirow{2}{*}{ Type of specimen } & \multirow{2}{*}{$\begin{array}{l}\text { Specimen } \\
\text { number }\end{array}$} & \multicolumn{3}{|c|}{ Tensile curves } & \multicolumn{2}{|c|}{$\begin{array}{l}\text { Measurements } \\
\text { on specimens }\end{array}$} & \multicolumn{2}{|c|}{ DIC measurements } \\
\hline & & $\begin{array}{c}\mathrm{YS} \\
(\mathrm{MPa})\end{array}$ & $\begin{array}{l}\text { UTS } \\
(\mathrm{MPa})\end{array}$ & $\begin{array}{c}A \\
(\%)\end{array}$ & $\begin{array}{c}Z \\
(\%)\end{array}$ & $\begin{array}{c}A \\
(\%)\end{array}$ & $\begin{array}{c}A \\
(\%)\end{array}$ & $\begin{array}{c}\varepsilon_{\max } \\
(\%)\end{array}$ \\
\hline \multirow[t]{6}{*}{ Hydrogenated } & 2 & 660 & 823 & 16 & 46 & 16 & 16 & 43 \\
\hline & 3 & 663 & 825 & 16 & 47 & 16 & 16 & 43 \\
\hline & 4 & 664 & 823 & 16 & 46 & 16 & 16 & 44 \\
\hline & 5 & 662 & 822 & 16 & 42 & 16 & 16 & 43 \\
\hline & 6 & 653 & 820 & 15 & 42 & 16 & 16 & 44 \\
\hline & Average & $661 \pm 5$ & $822 \pm 3$ & $16 \pm 1$ & $44 \pm 3$ & $16 \pm 1$ & $16 \pm 1$ & $43 \pm 1$ \\
\hline \multirow[t]{6}{*}{ Annealed } & 11 & 621 & 775 & 17 & 48 & 18 & 18 & 49 \\
\hline & 12 & 606 & 763 & 18 & 49 & 17 & 18 & 45 \\
\hline & 13 & 641 & 761 & 17 & 53 & 17 & 18 & 43 \\
\hline & 14 & 637 & 758 & 18 & 54 & 17 & 17 & 47 \\
\hline & 15 & 645 & 763 & 17 & 53 & 17 & 18 & 46 \\
\hline & Average & $630 \pm 7$ & $764 \pm 6$ & $17 \pm 1$ & $51 \pm 3$ & $17 \pm 1$ & $18 \pm 1$ & $48 \pm 2$ \\
\hline
\end{tabular}
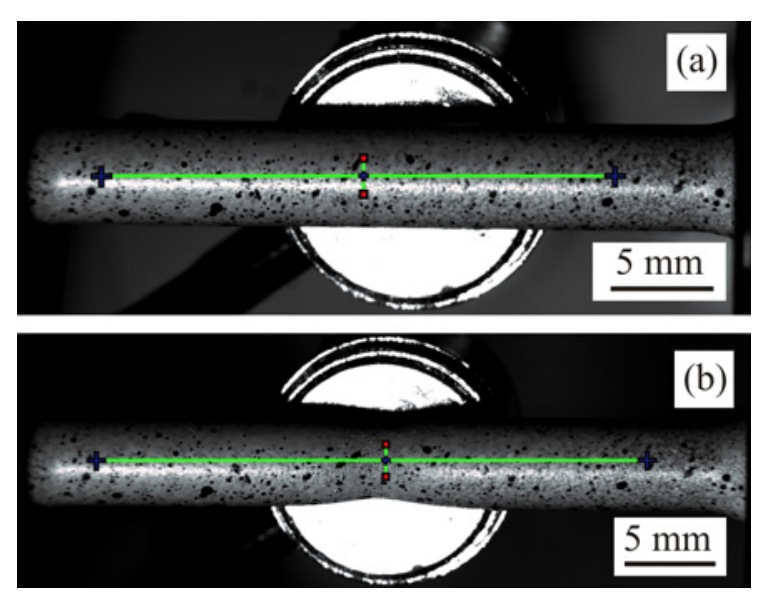

Fig. 6. Pictures of a tensile specimen taken by the CCD cameras: (a) before deformation, (b) after deformation.

elongation to fracture and reduction of the area are lower by 6.3 and $15.9 \%$ for the hydrogenated specimens when compared to those of the annealed ones. In addition, the DIC measurements also allow calculating maximum values of local strains $\left(\varepsilon_{\max }\right)$ from the experimentally measured displacement fields during the entire tensile tests. The calculated values of $\varepsilon_{\max }$ are comparable with the reduction of area values measured directly on the tensile specimens after the fracture.

Figure 6 shows the typical pictures of the tensile specimen taken by the CCD cameras. The random black colour speckles pattern is very well visible on the gauge surface before and after tensile testing [7, 8]. The green line along the gauge section of the spec- imen is drawn by the video extensometer of Mercury RT software before (Fig. 6a) and after tensile testing (Fig. 6b) allowing to monitor whole deformation process. The specimen shows non-uniform deformation with well-developed necked region before fracture.

Another advantage of Mercury software is also the possibility of measurement of Poisson's ratio, which can be described by equation in the following form

$$
\mu=\left|\frac{\mathrm{d} \varepsilon_{\text {trans }}}{\mathrm{d} \varepsilon_{\text {axial }}}\right|,
$$

where $\mu$ is the resulting Poisson's ratio, $\varepsilon_{\text {trans }}$ is the transversal strain (negative for axial tension and positive for axial compression), and $\varepsilon_{\text {axial }}$ is the axial strain (positive for axial tension and negative for axial compression). The average values of Poisson's ratio measured by Mercury software are $\mu=(0.29 \pm 0.01)$ and $\mu=(0.31 \pm 0.01)$ for the hydrogenated and annealed specimens, respectively. These values were used as input data for numerical simulation by FEA.

Figures $7 \mathrm{a}$ and $7 \mathrm{~b}$ show a $3 \mathrm{D}$ visualisation of $\varepsilon_{x}$ strain fields measured by the DIC method on the surface of the hydrogenated and annealed specimens tested to fracture, respectively. Both figures indicate highly non-uniform deformation with extensive necking characterised by a maximum local strain in the $x$-direction of 44.2 and $49.6 \%$ for the hydrogenated and annealed specimens, respectively.

Figures $8 \mathrm{a}$ and $8 \mathrm{~b}$ show a $3 \mathrm{D}$ visualisation of $\varepsilon_{x}$ strain fields calculated by FEA indicating the local deformation along the gauge section of the hydrogenated and annealed specimens tested to fracture, respectively. Both figures indicate highly non-uniform 
(a)

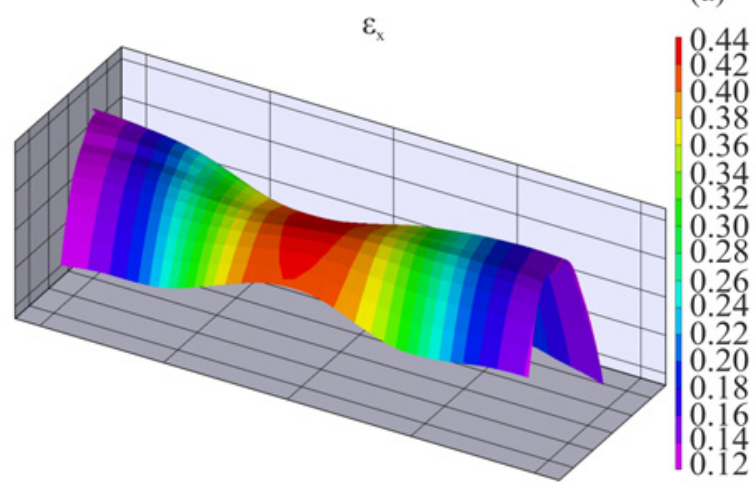

(b)

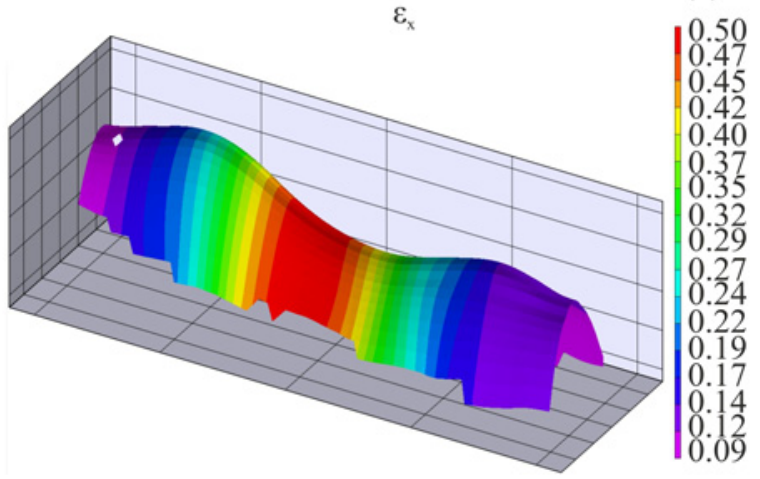

Fig. 7. Calculated strain fields $\varepsilon_{x}$ by the DIC method for the (a) hydrogenated and (b) annealed specimens.

(a)

$\varepsilon_{\mathrm{x}}$

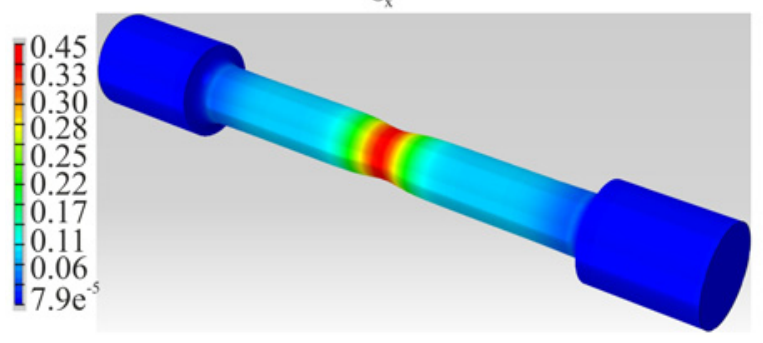

(b)

$\varepsilon_{\mathrm{x}}$

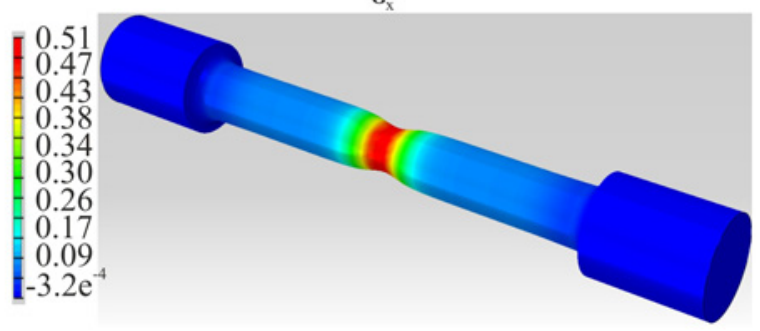

Fig. 8. Calculated strain fields $\varepsilon_{x}$ by the FEA method for (a) hydrogenated and (b) annealed specimens.

deformation with extensive necking characterised by a maximum local strain in the $x$-direction of 45.3 and $51.1 \%$ for the specimen hydrogenated and annealed, respectively. Very good agreement between the strain fields calculated by the experimental DIC method and those resulting from the FEA calculations indicates the appropriateness of the input data experimentally determined for the studied steel in the frame of this work.

\subsection{Work hardening behaviour}

Measurements of elongation and reduction of the area by the DIC method during entire tensile deformation enable to calculate true stresses and true strains along the gauge section of the specimens. Figure 9 shows the true stress and true strain curves calculated assuming engineering, uniform, non-uniform and local deformation of the gauge section. For the engineering curve (black curve in Fig. 9) the stresses and strains are obtained from the tensile machine and extensometer, respectively. For the uniform deformation (blue curve in Fig. 9), the true stresses $\sigma_{\mathrm{t}}$ are calculated assuming uniform contraction along the entire gauge section as a function of the elongation. The average true strains $\varepsilon_{\mathrm{t}}$ are calculated from the engineering strains $\varepsilon$ according to the relationship $\varepsilon_{\mathrm{t}}=\ln (1+\varepsilon)$. For the non-uniform deformation (green curve in Fig. 9), the true stresses are calculated assuming the experimentally measured contractions (maximum values) by the DIC method and assuming the calculated average true strains $\varepsilon_{\mathrm{t}}$. For the local deformation (red curve in Fig. 9), the true stresses are calculated assuming measured reduction of area (maximum values) by the DIC method and true local strains calculated from the average local engineering strains measured for the necked region. The diagrams clearly indicate that the values of true deformation are lower and the values of the true stresses are higher for the specimens annealed in hydrogen than those of the specimens annealed in argon.

Figure 10 shows the evolution of work hardening rate $\Theta$ with the true strain. The work hardening rate $\Theta$ is calculated as

$$
\Theta=\frac{\mathrm{d} \sigma_{\mathrm{t}}}{\mathrm{d} \varepsilon_{\mathrm{t}}}
$$

It is clear from Figs. 10a-c that the work hardening rates for the uniform, non-uniform and local deformations differ for the hydrogenated specimens from those of annealed ones up to the true strains of about 

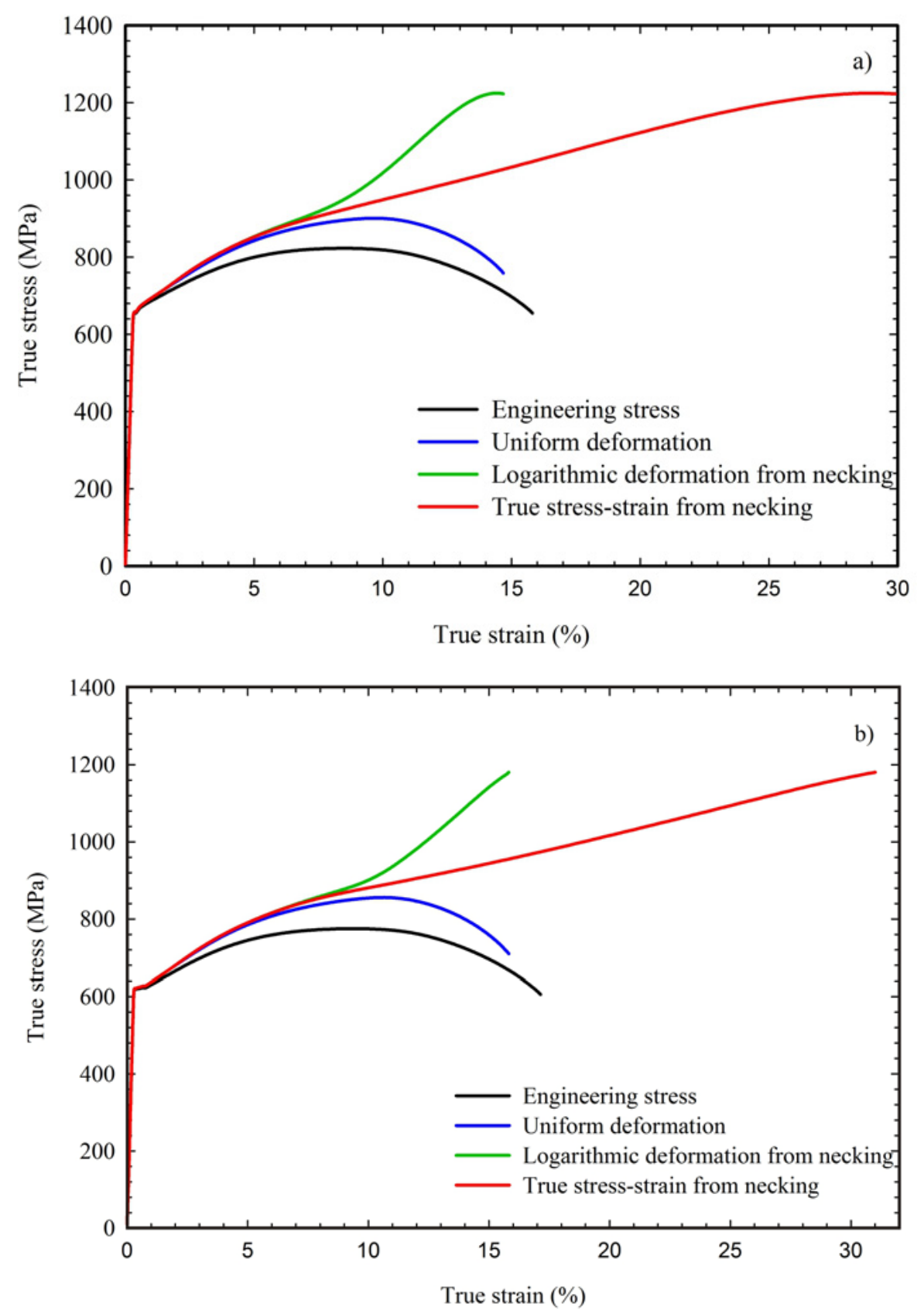

Fig. 9. Examples of the stress-strain tensile curves calculated assuming engineering, uniform, non-uniform and local deformation of (a) hydrogenated and (b) annealed specimens.

$3 \%$. For the true strains higher than $3 \%$, the work hardening rate continuously decreases with increasing true strain up to the tensile fracture for the uniform and local deformation (Figs. 10a and 10c). For the non-uniform deformation (Fig. 10b), the work hardening rate slightly decreases with increasing $\varepsilon_{\mathrm{t}}$ and starts to increase rapidly after achieving a true strain of about $8 \%$. For the local deformation (Fig. 10c), the work hardening rate decreases to a minimum value of about $1200 \mathrm{MPa}$ at $\varepsilon_{\mathrm{t}}$ of about $10 \%$ and then slightly increases with increasing true strain up to the tensile fracture. It should be noted that three stages of the work hardening were also reported by Zuo et al. [21] for medium carbon low alloy steels when analysed in terms of true deformation.

\subsection{Microstructure after tensile testing}

Figure 11 shows the typical microstructure in the gauge section of the tensile specimens. The ferritic grains and pearlitic colonies of both hydrogenated (Fig. 11a) and annealed (Fig. 11b) specimens are elongated in a direction close to their tensile axis. Numerous cavities formed predominantly at ferritic/pearlitic 

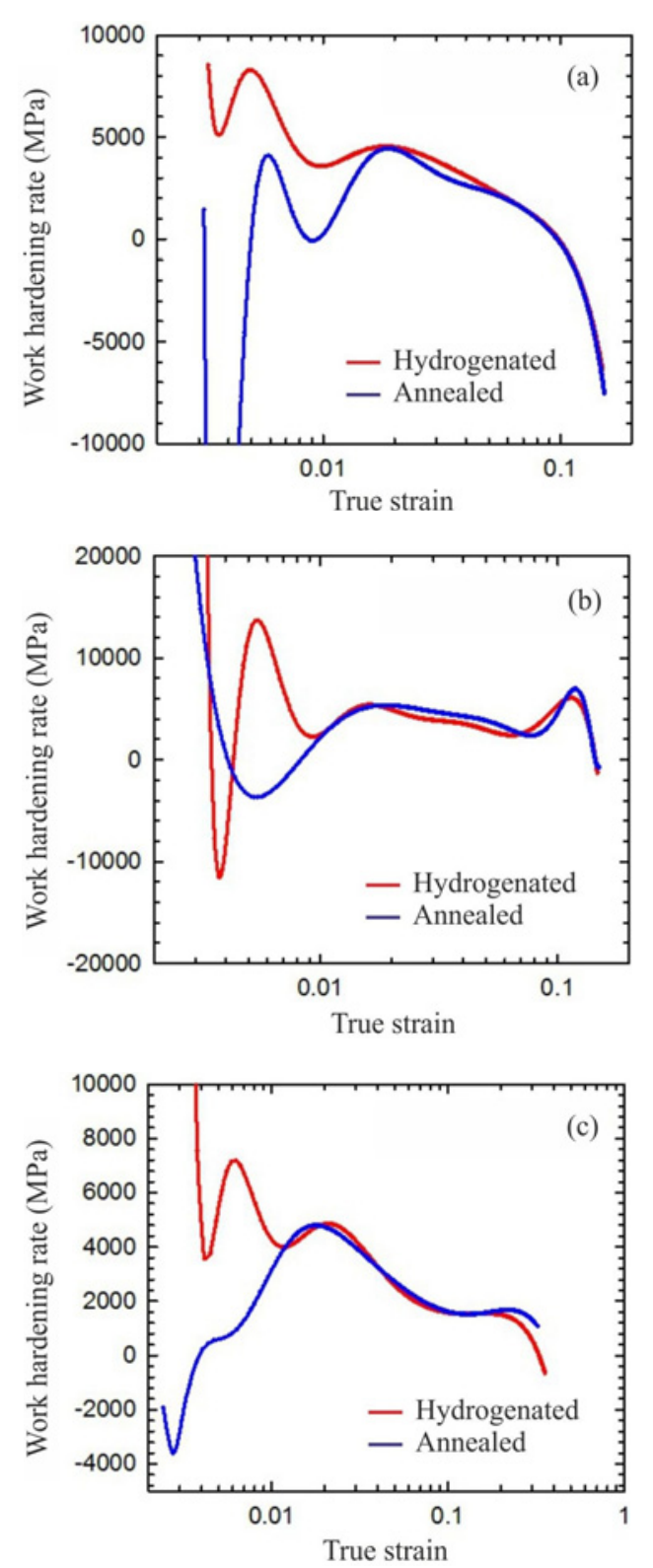

Fig. 10. Dependence work hardening rate on true strain calculated for (a) uniform, (b) non-uniform and (c) local tensile deformation of the hydrogenated and annealed specimens.

grain boundaries as well as large cracks propagating through the ferritic grains can be well identified in the necked region. The extent of plastic deformation can also be quantified using the results of quantitative image analysis of the microstructure in the necked region of the tensile specimens, where maximum local strains $\varepsilon_{\max }$ in the $x$ direction are calculated to be 44.2 and $49.6 \%$ for the hydrogenated and annealed specimens, respectively. For this purpose, true strain of the major axis $\varepsilon_{\text {maj }}$, true strain of the minor axis $\varepsilon_{\text {min }}$ and change of the shape factor $\Delta F$ are calculated according to the
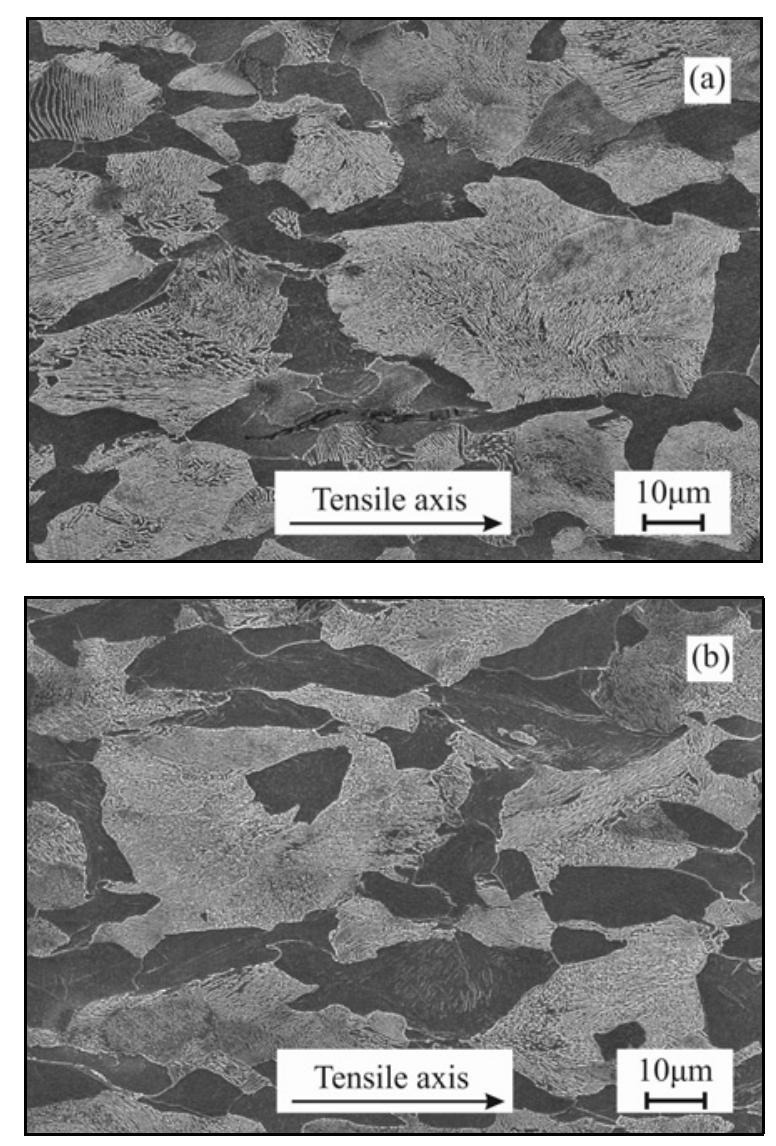

Fig. 11. Typical SEM micrographs of the longitudinal section in the vicinity of the fracture surface of (a) hydrogenated, (b) annealed specimen.

following relationships:

$$
\begin{gathered}
\varepsilon_{\mathrm{maj}}=\ln \left(1+\left[\frac{l_{\mathrm{maj}_{\mathrm{a}}}+l_{\text {maj }_{\mathrm{b}}}}{l_{\mathrm{maj}_{\mathrm{b}}}}\right]\right) \times 100, \\
\varepsilon_{\mathrm{min}}=\ln \left(1+\left[\frac{l_{\text {min }_{\mathrm{a}}}+l_{\text {min }_{\mathrm{b}}}}{l_{\text {min }_{\mathrm{b}}}}\right]\right) \times 100, \\
\Delta F=\left[\frac{F_{\mathrm{a}}+F_{\mathrm{b}}}{F_{\mathrm{b}}}\right] \times 100,
\end{gathered}
$$

where $l_{\text {maja }_{\mathrm{a}}}, l_{\text {maj }_{\mathrm{b}}}, l_{\text {mina }_{\mathrm{a}}}, l_{\text {min }_{\mathrm{b}}}, F_{\mathrm{a}}$, and $F_{\mathrm{b}}$ are the length of the major axis after deformation, length of the major axis before deformation, length of the minor axis after deformation, length of the minor axis before deformation, shape factor after deformation and shape factor before deformation, respectively. The calculated results are summarised in Table 3 . It is clear that the hydrogenated specimens show lower values of $\varepsilon_{\mathrm{maj}}, \varepsilon_{\min }$ and $\Delta F$ than those calculated for the specimens annealed in argon. These changes of the local deformation of ferritic grains and pearlitic colonies can 
Table 3. Microstructure characterisation of tensile specimens before and after tensile testing

\begin{tabular}{|c|c|c|c|c|c|}
\hline \multirow{2}{*}{$\begin{array}{l}\text { Microstructure } \\
\text { Type of specimen }\end{array}$} & & \multicolumn{2}{|c|}{ Pearlitic } & \multicolumn{2}{|c|}{ Ferritic } \\
\hline & & Hydrogenated & Annealed & Hydrogenated & Annealed \\
\hline \multirow[t]{3}{*}{ Before deformation } & Length of major axis $(\mu \mathrm{m})$ & $7.66 \pm 0.49$ & $7.02 \pm 0.18$ & $13.31 \pm 0.30$ & $13.46 \pm 0.24$ \\
\hline & Length of minor axis $(\mu \mathrm{m})$ & $3.32 \pm 0.19$ & $3.19 \pm 0.12$ & $5.74 \pm 0.14$ & $6.72 \pm 0.17$ \\
\hline & Shape factor $(-)$ & $0.45 \pm 0.04$ & $0.45 \pm 0.04$ & $0.48 \pm 0.05$ & $0.48 \pm 0.05$ \\
\hline \multirow[t]{3}{*}{ After deformation } & Length of major axis $(\mu \mathrm{m})$ & $14.98 \pm 0.76$ & $19.40 \pm 0.51$ & $15.20 \pm 0.35$ & $18.32 \pm 0.38$ \\
\hline & Length of minor axis $(\mu \mathrm{m})$ & $6.29 \pm 0.28$ & $6.79 \pm 0.18$ & $5.30 \pm 0.07$ & $5.95 \pm 0.08$ \\
\hline & Shape factor $(-)$ & $0.39 \pm 0.05$ & $0.38 \pm 0.05$ & $0.43 \pm 0.05$ & $0.41 \pm 0.04$ \\
\hline \multirow[t]{3}{*}{ Effect of deformation } & True strain of major axis, $\varepsilon_{\text {maj }}(\%)$ & 67 & 102 & 13 & 31 \\
\hline & True strain of minor axis, $\varepsilon_{\min }(\%)$ & 64 & 76 & 8 & 12 \\
\hline & Change of shape factor, $\Delta F(\%)$ & 13 & 16 & 10 & 15 \\
\hline
\end{tabular}

be related to the effect of hydrogen, which increases the yield strength and ultimate tensile strength on the expense of decreasing ductility of the studied ferritic-pearlitic steel.

\section{Conclusions}

The present study yields the following conclusions:

1. The annealing of the ferritic-pearlitic steel specimens in hydrogen increases room temperature offset $0.2 \%$ yield strength and ultimate tensile strength and decreases tensile elongation and reduction of the area when compared to those of the specimens annealed in argon.

2. The strain fields determined by the experimental 3D DIC method on the surface of the tensile specimens correspond very well to the $3 \mathrm{D}$ calculations of the strain fields performed by FEA using the input data for the studied steel measured in the frame of this work.

3. The evolution of the work hardening rate with true strain calculated assuming a uniform, nonuniform and local deformation of the hydrogenated tensile specimens is significantly different from that of the annealed specimens up to the true strains of about $3 \%$.

4. Quantitative metallographic analysis of ferritic grains and pearlitic colonies in the necked regions of the specimens before and after tensile deformation results in lower values of calculated true strains of the major axis, true strains of the minor axis and change of the shape factor of the hydrogenated specimens when compared to those of the specimens annealed in argon.

\section{Acknowledgements}

This work was financially supported by the Slovak Research and Development Agency under the contract
APVV-15-0660, the Slovak Grant Agency for Science under the contract VEGA 2/0125/16, Slovak Research and Development Agency under the contract APVV-0434-10 and the contract MVTS founding of the project INCAST and Long-term operation of nuclear power plants VVER 440 taking into account the environmental impact ITMS 26220220395, supported by the Research and Development Operational Program funded by the European Regional Development Fund.

\section{References}

[1] Lavender, J. D., Jones, F. W.: J. Iron Steel Inst., 9, 1949, p. 14.

[2] Tau, L., Chan, S. L. I.: Mater. Lett., 29, 1996, p. 143. doi:10.1016/S0167-577X(96)00140-1

[3] Bhadeshia, H. K. D. H., Honeycombe, R.: Steels Microstructure and Properties. 3rd Edition. Oxford, Butterworth-Heinemann 2006.

[4] Gladstein, L. I., Larionova, N. P., Belyaev, B. F.: Metallurgist, 56,2012 , p. 579. doi:10.1007/s11015-012-9619-3

[5] Chan, S. L. I., Charles, J. A.: Mater. Sci. Tech., 2, 1986, p. 956. doi:10.1179/mst.1986.2.9.956

[6] Štamborská, M., Lapin, J., Bajana, O., Losertová, M.: In: Proceedings of International Conference Mechanical Technologies and Structural Materials. Eds.: Jozić, S., Lela, B. Split, CSMT 2015, p. 161. ISSN 1847-7917.

[7] Štamborská, M., Lapin, J., Bajana, O.: In: Proceedings of International Conference Mechanical Technologies and Structural Materials. Eds.: Jozić, S., Lela, B. Split, CSMT 2016, p. 145. ISSN 1847-7917.

[8] Stamborská, M., Lapin, J., Bajana, O., Losertová, M.: Kovove Mater., 53, 2015, p. 399. doi:10.4149/km_2015_6_399

[9] Stamborská, M., Losertová, M., Konečná, K., Mareš, V., Horsák, L.: Kovove Mater., 53, 2015, p. 305. doi:10.4149/km_2015_5_305

[10] Stamborská, M., Mareš, V., Kvíčala, M., Horsák, L.: Kovove Mater., 52, 2014, p. 377. doi:10.4149/km_2014_6_377 
[11] Huang, J., Shi, D. Q., Yang, X. G., Pan, B., Shi, H.: Sci. China Tech. Sci., 57, 2014, p. 1411. doi:10.1007/s11431-014-5555-8

[12] Rossi, M., Pierron, F., Stamborská, M., Šimčák, F.: Experimental and Applied Mechanics, 4, 2013, p. 229. doi:10.1007/978-1-4614-4226-4_27

[13] Hagara, M., Schrötter, M.: AJME, 1, 2013, p. 185. doi:10.12691/ajme-1-7-6

[14] Schrötter, M., Hagara, M., Kalina, M.: Appl. Mech. Mater., 611, 2014, p. 490.

doi:10.4028/www.scientific.net/AMM.611.490

[15] Hua, T., Xie, H. M, Wang, S., Hu, Z. X., Chen, P. W., Zhang, Q. M.: Opt. Laser Technol., 43, 2011, p. 9. doi:10.1016/i.optlastec.2010.04.010

[16] Gao, J., Shang, H.: Appl. Optics, 48, 2009, p. 1371. $\underline{\text { doi:10.1364/AO.48.001371 }}$
[17] Garino, C. G., Gabaldón, F., Goicolea, J. M.: Finite Elem. Anal. Des., 42, 2006, p. 1187. doi:10.1016/j.finel.2006.05.004

[18] Sethuraman, R., Viswanadha, G. S.: Int. J. Pres. Ves. Pip., 81, 2004, p. 313. doi:10.1016/j.ijpvp.2004.03.002

[19] Ince, A., Glinka, G.: J. Strain Anal. Eng., 48, 2013, p. 229. doi: $10.1177 / 0309324713477638$

[20] Shaposhnikov, N. G.: C-Fe Phase Diagram. ASM Alloy Phase Diagrams Database. Materials Park, ASM International 2008.

[21] Zuoa, X., Chen, Y., Wang, M.: Mat. Res., 15, 2012, p. 915. doi:10.1590/S1516-14392012005000118 